\title{
THE DEVELOPMENT OF TIME SENSE
}

\author{
ICHIO MORI ${ }^{1}$ \\ Osaka University of Education
}

\begin{abstract}
The aim of the experiment was to investigate the development of the subjective time scale in clildren. Findings were as follows: (a) The subjective past time scale of 9-year-old children and 11-year-old children consists of two parts, one is the part in which subjective time $(Y)$ can be described by a linear function of objective time $(\mathrm{I})$, and the other is the part in which $Y$ can be described by a power function of $X$. (b) The region described by a linear function expandis with the increase in age. (c) The linear functions adopted in the groups of children camot represent the fit estimation of objective time, while it can represent this estimation in the case of adults.
\end{abstract}

When we judge which of two past events is more distant in time, our judgement is alwars based on a time scale which is graduated on a subjective time axis. There is no doubt that the investigation of the subjective time scale in children will be very useful for science education, because the subjective time scale of them must be built up properly for a correct understanding of the change of various phenomena. A number of research projects regarding the subjective time scale have been reported mainly from the psychophysical point of view. But most of these works (Ross \& Katchmar, 1951; Ekman \& Frankenhaeuser, 1957; Stevens \& Galanter, 1957) has been concerned with scale in the order of seconds. At present, we have only few reports on research concerning the subjective time scale beyond $60 \mathrm{sec}$.

Cohen, Hansel, and Sylverster (1954) reported that the subjective time increases linearly as the objective time increases logarithmically up to a period about six months, and beyond this period, subjective time is approximately in direct

1 The author wishes to his gratitude to $\mathrm{Mr}$. Shinya Taira who carried out the present experiments for his help in collecting the data.

Requests for reprints should be sent to Ichio Mori, Osaka University of Education, Osaka, 543 Japan. proportion to the objective time. In this experiment, he gave each of the subjects a sheet of paper on which was drawn a line $25.4 \mathrm{~cm}$ in length. After giving the instruction that the line represents the subject's life from "birth" to " now" he asked them to put marks along the line showing the given intervals. On the other hand, in the case of Ekman and Lundverg (1971), it was reported that subjective time distance is a power function of objective time. And in his experiment, the subjects' estimated intervals extended over 200 years each for both past and future directions. The stimuli were points in time defined as year numbers (or terms of generation). Subjects were presented with all possible combinations of stimuli on printed forms and were asked to indicate which of the two stimuli consisting of a pair were perceived as being more distant in time, and to estimate the perceived distance of other stimuli, expressed as a percentage of the standard. However, we have no reports yet on any research which throws light upon the subjective time scale, adopting an hour or a day as a fixed interval for estimating a long distance of time.

The present study is intended to examine the subjective time scale by obtaining the subjects' time estimation of the interval from "now" to an event in com- 
parison with the fixed interval (1 day).

If the subjects can estimate past time correctly leading to the fixed interval, subjective time scale can be said to be a correct one, graduated equally in temporal length.

In case of younger children, they will be able to give a fairly correct estimation, when the past time is not so far from "now"; but they will not, when the past time is rather far from "now". We suppose that it is because they have a subjective time scale which is unequally graduated in distance.

The purpose of present study is to make the above-mentioned problem clear by examining two fundamental hypotheses proposed as follows.

\section{Hypothesis}

(1) The subjective time scale of younger children is equally graduated only in the region where the degree of retrospect is small (the region not so far from " present"), and beyond this region they are apt to underestimate the actual interval. In other words, the region in which subjective past time of younger children $(Y)$ is described by a linear function of objective time $(X)$, is limited only to the range where $X$ is small. If the degree of retrospect exceeds such a limit, a mathematical description shows a noticeable trend of negatively accelerated growth.

(2) The subjective time scale of younger children is equally graduated only in the region where the degree of retrospect is small, and with an increase in age, the part equally graduated expands into the region where the degree of retrospect is large. In other words, the region in which the subjective past time $(Y)$ is described by a linear function of objective time $(X)$ will expand.

\section{Method}

\section{Subjects}

It is not until the age of nine or so that children succeed in constructing a time scale embracing all moments and all events by means of the qualitative operation of duration and the measurement of time (Piaget, 1927). The subjects of nine and above who can retrace the course of events well enough and construct temporal sequences (Piaget, 1927) were chosen and divided into four groups as follows:

Group 1: 9-year-old children in third grade in elementary school.

Group 2: 11-year-old children in the ffth grade in elementary school.

Group 3: 13-year-old children in the first grade in junior high school.

Group 4: 22-year-old students in college (adults).

\section{Procedure}

Each subject was given a white tape made of cloth, $2.5 \mathrm{~cm}$ in width and $4 \mathrm{~m}$ in length. On the tape, two indexes were printed (the black line indicating "now" and the red one indicating the time just one day before "now"). So, the fixed interval between these two lines represented the length of a "day". One end of the tape presented was rolled and could be extended for 5-6 $\mathrm{m}$, if necessary.

The subjects were asked to recall past events and to indicate their position on the tape relating to the fixed interval. When the experimenter asked the subjects to recall past events, stimuli $A-G$ in Table 1 were used for group 1 , A-M for group 2, A-S for group 3, and A-S for group 4. No temporal order was given when the past events were presented to subjects. Whenever the subjects finished estimating an interval, the experimenter required them to go back to the position representing "now" and asked them to estimate the given intervals in relation to the fixed interval. The respective dates when the experiments were carried out were:

Group 1: September 16th, 1977

Group 2: November 30th, 1977

Group 3: December 20th, 1977

Group 4: December 19th, 1977

The stimuli (past events) are shown in Table 
TABI.E

Stimuli (past event)

$\begin{array}{lll}\text { Group } & 1 & \mathrm{~A}(7) \mathrm{B}(15) \mathrm{C}(57) \mathrm{D}(71) \mathrm{E}(161) \mathrm{F}(260) \mathrm{G}(527) \\ \text { Group } & 2 & \mathrm{~A}(7) \mathrm{H}(59) \mathrm{I}(72) \mathrm{J}(236) \mathrm{F}(333) \mathrm{K}(365) \mathrm{L}(498) \mathrm{M}(601) \\ \text { Group } & 3 & \mathrm{~A}(7) \mathrm{N}(67) \mathrm{H}(81) \mathrm{O}(227) \mathrm{P}(263) \mathrm{F}(353) \mathrm{K}(365) \mathrm{Q}(518) \mathrm{R}(621) \mathrm{S}(731) \\ \text { Group } 4 & \mathrm{~A}(7) \mathrm{T}(46) \mathrm{U}(110) \mathrm{V}(228) \mathrm{W}(262) \mathrm{F}(352) \mathrm{K}(365) \mathrm{X}(530) \mathrm{Y}(656) \mathrm{S}(731)\end{array}$

Note: Figures in parentheses represent the period (in days) from an event to the day of the experiment.

A: Day one week before experiment, B: September 1st, C: Day when the summer holiday began, D: Day of the Star Festival (traditional Japanese festival), E: Opening ceremony for third graders, F: New Year's Day this year, G: Opening ceremony for second graders, $\mathrm{H}$ : Sports Day (Japanese national holiday), I : Day when college students visited school, $\mathrm{J}$ : Opening ceremony from fifth graders, K: Day one year before experiment, $\mathrm{L}$ : Closing ceremony for fourth graders, $\mathrm{M}$ : Opening ceremony for fourth graders, $N$ : Day mid term examinations began, $O$ : Day of school picnic, P: Entrance ceremony day, $Q$ : Closing ceremony for first term of sixth graders, $R$ : Opening ceremony for first term of sixth graders, $S$ : Two years before experiment, $T$ : Day when college festival began, $U$ : Last day of summer vacation, $Y$ : Children's day (Japanese national holiday), W: April Fool's day, X: Day of Weaver Festival previous year, Y': Doll's Festival (traditional Japanese festival) previous year.

TABLE 2

Experimental conditions

\begin{tabular}{crrrrr}
\hline Group & $\begin{array}{c}\text { No. of } \\
\text { subjects }\end{array}$ & $\begin{array}{c}\text { Mean } \\
\text { age } \\
\text { yr. mo. }\end{array}$ & $\begin{array}{c}\text { No. of } \\
\text { stimuli }\end{array}$ & Fixed interval \\
\hline 1 & 73 & 9 & 0 & 7 & $1.0 \mathrm{~cm}(=1$ day $)$ \\
2 & 67 & 11 & 2 & 8 & $.6 \mathrm{~cm}$ (=1 day) \\
3 & 63 & 13 & 3 & 10 & $.5 \mathrm{~cm}$ (=1 day) \\
4 & 61 & 22 & 5 & 10 & $.5 \mathrm{~cm}$ (=1 day)
\end{tabular}

1 and the experimental conditions are shown as Table 2 .

\section{Results and Discussion}

Subjective time distance $\left(r_{i j}\right)$ was defined as follows;

the length between "now" $r_{i j}=\frac{\text { and an event } \mathrm{E} \text { on the tape }}{\text { the length between the two indexes }}$ where $i$ represents the number of stimuli (past events)

where $j$ represents the number of subjects

In the measured values, too large or too small ones were rejected by Thompson's method at 0.05 level of significance. Next, the relation between $X_{i}$ (objective time) and $Y_{i j}$ (subjective time) was ob- tained, using the method of least squares, and the significance of regression and the lack of fit by regression analysis were tested. It was found out that the relation between $X_{i}$ and $Y_{i f}$ is described by a linear function of $X$ when $X_{i}$ is small, and described by a power function of $X$ when $X_{i}$ is large.

The relation between subjective and objective time of 9-year-old children is shown in Fig. 1. It is evident from this figure that the subjective time scale in the region $0 \leqq X \leqq 71$ is equally graduated. As might be suspected, $r$ can be described by a linear function of $X$ in this range. Figure 1 also shows the tendency that beyond this region the subjects are apt to

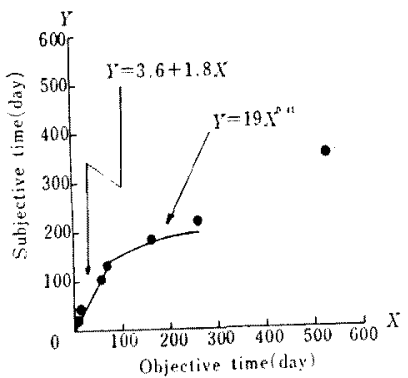

Fig. 1. Relation between subjective and objective time of 9-year-old children. 
TABLE 3

Regression analysis of time estimates (9-year-old children)

A) Analysis of variance of linear regression model

\begin{tabular}{|c|c|c|c|c|}
\hline SV & $\mathrm{SS}\left(X 10^{-2}\right)$ & $d f$ & $\operatorname{MS}\left(X_{1} 10^{-2}\right)$ & F \\
\hline Total & 4076 & 132 & & \\
\hline Regression & 2674 & 1 & 2674 & $249.9^{* *}$ \\
\hline Error & 1402 & 131 & 10.7 & \\
\hline Lack of fit & 28 & 3 & 9.3 & .85 \\
\hline Pure error & 1374 & 128 & 10.73 & \\
\hline$R^{2}=65.60$ & $\% \quad * * p<$ & .01 & & \\
\hline
\end{tabular}

B) Analysis of variance of power regression model

\begin{tabular}{lrrll}
\hline \multicolumn{1}{c}{ SV } & SS & $d f$ & MS & $F$ \\
Total & 3.962 & 51 & & \\
Regression & .476 & 1 & .476 & $6.83^{*}$ \\
Error & 3.486 & 50 & .0697 & \\
Lack of fit & 0 & 1 & 0 & 0 \\
Pure error & 3.486 & 49 & .07114 & \\
$R^{2}=12.0 \%$ & $*$ & $0<.05$ & & \\
Fitting curve : $Y=19 X^{0.41}(71 \leqq X \leqq 260)$
\end{tabular}

underestimate the actual interval. Hence, it is assumed that $Y$ can be described by a power function whose exponent is smaller than 1 in the region $X \geqq 71$. The results of regression analysis are shown in Table 3. The apportioning of the total variation in this manner reveals a significant variation accounted for by both posturated models and an insignificance of variation due to lack of fit. So we can conclude that the linear regression model in

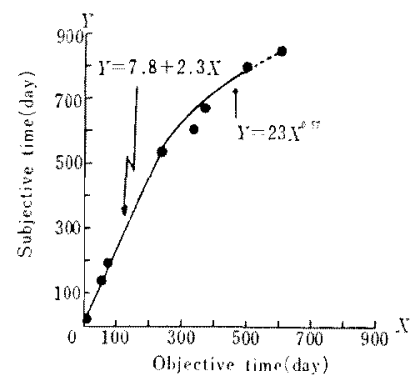

FIG. 2. Relation between subjective and objective time of 11-year-old children.
TABLE 4

Regression analysis of time estimates

(11-year-old children)

A) Analysis of variance of linear regression model

\begin{tabular}{lrrcr}
\hline \multicolumn{1}{c}{ SV } & $\mathrm{SS}\left(X 10^{-8}\right)$ & $d f$ & $\mathrm{MS}\left(X 10^{-8}\right)$ & $F$ \\
\hline Total & 9017 & 218 & & \\
Regression & 8004 & 1 & 8004 & $1715^{* *}$ \\
Error & 1013 & 217 & 4.668 & \\
Lack of fit & 36 & 3 & 12 & 2.6 \\
Pure error & 977 & 214 & 4.57 & \\
$\quad R^{2}=88.8 \%$ & $* *$ & $p<.01$ & & \\
Fitting straight line: $Y=7.8+2.3 X(0 \leqq X \leqq 236)$
\end{tabular}

B) Analysis of variance of power regression model

\begin{tabular}{lrrll}
\hline \multicolumn{1}{c}{ SV } & \multicolumn{1}{c}{ SS } & \multicolumn{1}{c}{$d f$} & MS & $F$ \\
\hline Total & 1.457 & 127 & & \\
Regression & .635 & 1 & .635 & $97.4^{* *}$ \\
Error & .822 & 126 & .00652 & \\
Lack of fit & .008 & 2 & .004 & .6 \\
Pure error & .814 & 124 & .00656 & \\
$\quad R^{2}=43.6 \%$ & $* * p<.01$ & & \\
Fitting curve $: Y=23 X^{0.57}(236 \leq X \leq 498)$ &
\end{tabular}

the region $0 \leqq X \leqq 71$ and the power function model in the region $71 \leqq X \leqq 260$ are statistically fitted to the data. In addition, regression analysis was again used to cxamine whether the linear function $r=$ $3.6+1.8 X$ can be taken to represent the "exact estimation" (i.e., if the actual intervals are correctly calculated the function will be $Y=X$ ). Though there was no significant difference between the intercepts 3.6 and $0(t=.97, d f=131)$, the two coefficients (1.8 and 1$)$ were significantly different $(t=1.7, d f=131, p<.05)$. The above result shows that the subjects cannot exactly estimate the objective past time.

The relation between subjective and objective time of 11-year-old children is shown in Fig. 2. The broken line in this figure represents those parts for which fitting of a power function was statistically impossible. In Fig. 2, the region in which $Y$ can be described by a linear function of $X$ is larger in comparison with that of 9- 
year-old children, and $i$ can be described by a power function in the region $X \geq 236$. The results of regression analysis are shown in Table $t$. It is evident from the tables that the linear regression model in the region $0 \leqq A \leqq 236$, and the power function model in the region $236 \leqq I \leqq 498$ are statistically applicable.

In addition, regression analysis was used to examine whether the linear function $y=7.8+2.3 . I^{*}$ can be used as the exact estimation of objective time of which function must be represented by $Y=X$. Though there was no difference in the two intercepts 7.8 and $0(t=1.4, d f=217)$, the two coefficients 2.3 and 1 were significantly different $(t=4.0, d f=217, p<$ $.05)$. According to the result, the equation $Y=7.8+2.3 \mathrm{Y}$ cannot be used as the exact estimation of objective time.

The relation between subjective and objective time of 13-year-old children is shown in Fig. 3. The region in which $Y$ can be described by a linear function of $X$ is larger in comparison with those of 9year- and 11-year-old children. The results of regression analysis are shown in Table 5. As is evident from Table 5, the linear regression is statistically fitted to the data in the region $0 \leqq X \leqq 365$. Besides, the regression analysis was used to examine whether the linear function $Y=$ $6.5+1.7 X$ can be used as the exact estimation of objective time. Though there was no difference between the two intercepts 6.5 and $0(t=.83, d f=351)$, the two coef-

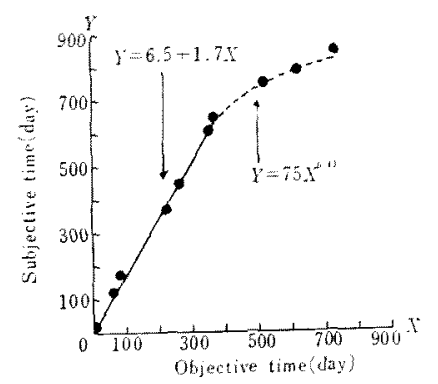

FIg. 3. Relation between subjective and objective time of 13-year-old children.
TABEE 5

Analysis of variance of linear regression model

(13-yearmold children)

\begin{tabular}{lrrcr}
\hline \multicolumn{1}{c}{$\mathrm{SV}$} & $\mathrm{SS}\left(X 10^{-4}\right)$ & df & $\mathrm{MS}\left(X 10^{-4}\right)$ & $F$ \\
\hline Total & 2100 & 352 & & \\
Regression & 1746 & 1 & 1746 & $1730^{* *}$ \\
Error & 354 & 351 & 1.01 & \\
Lack of fit & 8 & 6 & 1.33 & 1.3 \\
Pure error & 346 & 345 & 1.00 & \\
$\quad R^{2}=83.1 \%$ & $* *$ & $p<.01$ & & \\
Fitting straight line: $Y=6.5+1.7 X(0 \leqq X \leqq 365)$
\end{tabular}

ficients (1.7 and 1) were significantly different $(t=3.0, \quad d f=351, \quad p<.05)$. The results indicate that the linear function $r=6.5+1.7 X$ cannot be used as the correct estimate. In addition, fitting of a power function $Y=75 X^{0.43}$ obtained by the method of least squares was statistically impossible for the region $X>365$, as a result of regression analysis.

The relation between subjective and objective time of adults is shown in Fig. 4 and the result of regression analysis is shown in Table 6. To determine whether the linear function $r=-2.4+1.2 X$ can be used as the correct estimation of objective time, regression analysis was used. There was no significant differences between the two intercepts -2.4 and 0 $(t=41, d f=438)$, and the two coefficients 1.2 and 1 were not significantly different $(l=1.0, d f=438)$. According to the result, the linear function adopted can re-

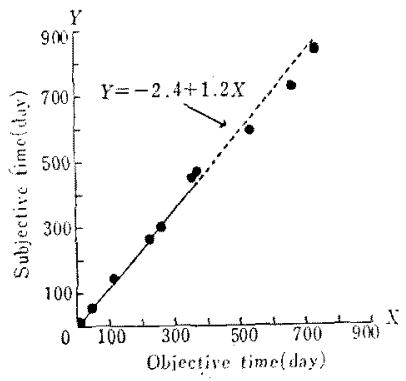

Frc. 4. Relation between subjective and objective time of adults. 
16.1

TanLe 6

Analysis of variance of lincar regression model

(adults)

\begin{tabular}{|c|c|c|c|c|}
\hline SV & $\operatorname{SS}\left(X 10^{-4}\right)$ & $d f$ & $\operatorname{MS}\left(X_{10}-4\right)$ & $F$ \\
\hline Total & 1670 & 439 & & \\
\hline Regression & 1367 & 1 & 1367 & $1980^{* *}$ \\
\hline Lrror & 303 & 438 & .692 & \\
\hline Lack of lit & 6 & 6 & 1 & 1.5 \\
\hline Pure error & 297 & 432 & .688 & \\
\hline $\begin{array}{l}R^{2}=81.9 \\
\text { ritting st }\end{array}$ & $\begin{array}{l}{ }^{*} p<1 \\
\text { raight line: }\end{array}$ & $\begin{array}{l}.01 \\
r\end{array}$ & $2.4+1.2 X$ & $\leqq 365)$ \\
\hline
\end{tabular}

present the exact estimation of objective time in case of adults.

\section{Conclusions}

The results can be summarized as follows:

1. The subjective past time scalc of 9year-old children and 11-year-old children consists of two parts, one is the part in which subjective time (1) can be described by a linear function $\left(X=a X^{n}+\right.$ $b ; a, b$ and $n$ are constants. $a>0, n=1$ ) of objective time $(X)$, and the other is the part in which $Y$ can be described by a power function $\left(Y=a X^{n}+b, a>0, b=0\right.$, $0<n<1$ ) of $X$.

2 . The region in which $Y$ can be described by a linear function of $X$ expands
I. Mori

with the increase in age; namely, in proportion to the increase in age, the subjective time scale equally graduated in temporal length expands into the region where the degree of retrospect is large.

3. The linear functions adopted in the groups of children cannot represent the exact estimation of objective time, while it can represent in case of adults.

\section{REFERENCES}

Cohen, J., Hansel, C.E.M., \& Sylverster, J. D. 1954 An experimental study of comparative judgements of time. British Journal of $P_{s y-}$ chology, 45, 108-114.

Ekman, G., \& Frankenhaeuser, M. 1957 Subjective time scales. Report Psychological Laboratories, No. 49, University of Stockholm.

Eкman, G., \& Lundeverg, G. 1971 Emotional reaction to past and future events as a function of temporal distance. Acta Psychologica, 35, $430-441$.

Piaget, J. 1927 Le developpment de la notion de temps chez l'enfant. Presses Universitaires de France.

Ross, S., \& Katchmar, M. 1951 The construction of a magnitude function for short time intervals. American Journal of Psychology, 64, $397-401$.

Stevens, S. S., \& Galanter, E. H. 1957 Ratio scales and category scales for a dozen perceptual continua. Journal of Experimental Psychology, 54, 377-411.

(Received April 3, 1979) 